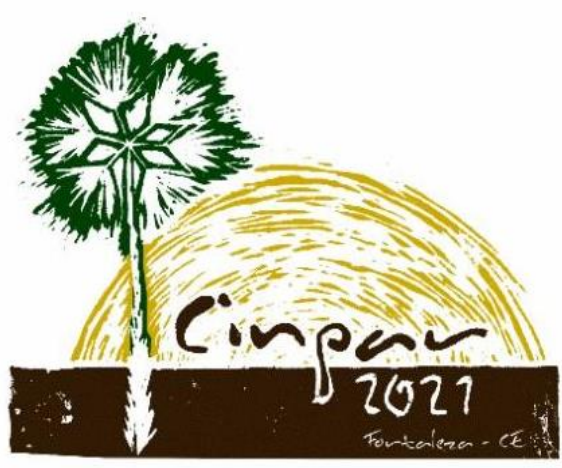

XVII Congresso Internacional sobre Patologia e

Reabilitação das Construções

XVII Congreso Internacional sobre Patología y Rehabilitación de las Construcciones

XVII International Conference on Pathology and Constructions Rehabilitation

FORTALEZA (Brasil), 3 a 5 de junho de 2021

https://doi.org/10.4322/CINPAR.2021.122

\title{
A influência da utilização de cinza pesada como substituição ao agregado miúdo natural em argamassa
}

\section{The influence of using heavy bottom ash as a substitute for natural fine aggregate in mortar}

\author{
André V. S. RIBEIRO ${ }^{1}$, Jéssyca Mendes da SILVA ${ }^{2}$, Rafael Dors SAKATA ${ }^{3}$, Francine PADILHA ${ }^{4}$, Eduardo Nobre \\ GUINDANI $^{5}$, Julia Beatriz Saugo MILANI ${ }^{6}$ \\ ${ }^{1}$ Programa de Pós-Graduação de Engenharia Civil, Universidade Federal de Santa Catarina, Florianópolis, Brasil. \\ andrecivilutfpr@gmail.com \\ 2 Programa de Pós-Graduação de Engenharia Civil, Universidade Federal de Santa Catarina, Florianópolis, Brasil. \\ eng.jessycam@gmail.com \\ 3 Programa de Pós-Graduação de Engenharia Civil, Universidade Federal de Santa Catarina, Florianópolis, Brasil. \\ rafaelsakata@gmail.com \\ 4 Programa de Pós-Graduação de Engenharia Civil, Universidade Federal de Santa Catarina, Florianópolis, Brasil. \\ francine.padilha1609@gmail.com \\ 5 Programa de Pós-Graduação de Engenharia Civil, Universidade Federal de Santa Catarina, Florianópolis, Brasil. \\ eduardo.guindani@gmail.com \\ 6Departamento de Engenharia Civil, Universidade Tecnológica Federal do Paraná, Pato Branco, Brasil. \\ juliabmilani1@gmail.com
}

\begin{abstract}
Resumo: A utilização da cinza pesada em seu estado bruto em substituição à areia natural em argamassas pode trazer benefícios ambientais e econômicos para os usuários, uma vez que não é necessário realizar processos como queima ou moagem e proporcionar uma destinação para o rejeito. Sendo assim, este artigo visa analisar as propriedades do estado fresco e endurecido de argamassas produzidas com a substituição parcial de areia natural por cinza pesada não beneficiada. A utilização da cinza pesada foi feita em substituição em massa ao agregado miúdo natural nos teores de 0,20\%,40\% e $60 \%$, utilizando uma faixa granulométrica entre $75 \mu \mathrm{m}$ e $600 \mu \mathrm{m}$. Os resultados para o estado fresco mostraram que a com o aumento da porcentagem de utilização da cinza pesada aumentou a demanda por aditivo dispersante para obtenção de argamassas de mesma consistência. No estado endurecido infere-se que a cinza pesada possa ser utilizada em substituição parcial ao agregado natural sem gerar perda no desempenho da matriz cimentícia.
\end{abstract}

Palavra-Chave: Cinza pesada, argamassa, estado fresco e estado endurecido

\begin{abstract}
The use of heavy ash in its raw state as a substitute for natural sand in mortars can bring environmental and economic benefits to users, since it is not necessary to perform processes such as burning or grinding and provide a destination for the waste. Therefore, this article aims to analyze the properties of the fresh and hardened state of mortar produced with the partial replacement of natural sand with heavy ash not benefited. The use of heavy ash was made in mass substitution to the natural fine aggregate in the contents of $0,20 \%, 40 \%$ and $60 \%$, using a size range between $75 \mu \mathrm{m}$ and $600 \mu \mathrm{m}$. The results for the fresh state showed that the increase in the percentage of use of heavy ash increased the demand for dispersing additives to obtain mortars of the same consistency. In the hardened state, it is inferred that the heavy ash can be used in partial replacement to the natural aggregate without generating loss in the performance of the cementitious matrix.
\end{abstract}

Keyword: Heavy ash, mortar, fresh state and hardened state 
A utilização de materiais que, geralmente, não têm uma destinação adequada, e que não comprometem as propriedades de matrizes cimentícias, têm sido objetos de pesquisas na área da construção civil. Esses materiais normalmente são utilizados conforme suas características, podendo ser utilizados em substituição ao ligante hidráulico e/ou aos agregados. Atualmente insumos como a cinza volante, escória granulada de alto-forno e filer, são empregados em substituição ao clínquer de cimento Portland para produção de cimentos com menor consumo de clínquer.

Entretanto um subproduto proveniente de usinas termelétricas que não tem uma destinação adequada, o qual é nocivo ao meio ambiente, é a cinza pesada. Essa cinza é resultado da queima a seco de carvão mineral. Este material tem características por ser um resíduo inorgânico grosso, poroso, com uma coloração cinza escura e com uma granulometria predominantemente de agregado miúdo (FEDERAL HIGHWAY ADMINISTRATION, 1998).

A indústria da construção civil gera muitos impactos ambientais negativos, como por exemplo, a produção do clínquer que gera gases poluentes ao meio ambiente. Estima-se que para cada tonelada produzida de cimento Portland seja emitida uma tonelada de gases poluentes (MEYER, 2009). Entretanto, não é só a produção de clínquer que gera impactos ambientais negativos, a retirada de areia natural de leitos de rios também contribui para esse processo de degradação. Assim, um subproduto disponível no meio ambiente que possa substituir um agregado natural, o qual sua disponibilidade depende de ações prejudiciais ao meio ambiente, é de grande relevância.

Jaturakitakkul e Cheerarot (2003) Singh e Siddique (2014), relatam em seus estudos que a granulometria da cinza pesada é semelhante a granulometria de agregados miúdos naturais (como a areia). Além disso Singh (2018), mostra que o material passante da peneira $600 \mu \mathrm{m}$ é cerca de $10 \%$ a $60 \%$ do total, e ainda que o material passante da peneira de $75 \mu \mathrm{m}$ seria menos do que $15 \%$ do total.

Dessa forma, verifica-se que a utilização de um material que em substituição ao agregado natural que possa mitigar e/ou diminuir os impactos ambientais negativos ocasionados pelo processo de extração do agregado natural é ambientalmente relevante. Nesse contexto, justifica-se a importância e relevância dessa pesquisa que se propõe ao estudo das propriedades no estado fresco e endurecido de argamassas confeccionadas com cinza pesadas não beneficiadas em substituição da areia natural.

\section{Materiais e métodos}

Os materiais utilizados no presente estudo foram: ligante hidráulico: cimento Portland CP V - ARI; areia fina natural; aditivo dispersante de terceira geração; água, proveniente do sistema de abastecimento de Florianópolis, Santa Catarina. O cimento Portland CP V-ARI (Alta Resistência Inicial) foi utilizado pois ele é o cimento com maior grau de pureza encontrado na região. A sua caracterização química e física está descrita na tabela 1.

Tabela 1 - Caracterização Física e Química do cimento

\begin{tabular}{|c|c|}
\hline \multicolumn{2}{|c|}{ Análise Física } \\
\hline Massa específica (Kg/dm³ $)$ & 3,09 \\
\hline Superfície específica de Blaine $\left(\mathrm{cm}^{2} / \mathrm{g}\right)$ & 4698 \\
\hline Início de Pega (min) & 217 \\
\hline Fim de Pega (min) & 277 \\
\hline Análise Química & 4,8 \\
\hline Perda ao Fogo (\%) & 1,6 \\
\hline Resíduo insolúvel (\%) & 17,5 \\
\hline $\mathrm{SiO}_{2}(\%)$ & 4,4 \\
\hline $\mathrm{Al}_{2} \mathrm{O}_{3}(\%)$ & \\
\hline
\end{tabular}




\begin{tabular}{|c|c|}
\hline $\mathrm{Fe}_{2} \mathrm{O}_{3}(\%)$ & 2,9 \\
\hline $\mathrm{CaO}(\%)$ & 59,9 \\
\hline $\mathrm{C} 3 \mathrm{~S}(\%)$ & 55,8 \\
\hline $\mathrm{C} 2 \mathrm{~S}(\%)$ & 9,96 \\
\hline $\mathrm{C} 3 \mathrm{~A}(\%)$ & 3,1 \\
\hline $\mathrm{C} 4 \mathrm{AF}(\%)$ & 9,59 \\
\hline
\end{tabular}

Os insumos foram obtidos através da colaboração de empresas da região de Florianópolis - Santa Catarina. Para a caracterização desses materiais foram feitos ensaios de granulometria e massa específica conforme a ABNT NBR NM 248 (2003) e ABNT NBR 6508 (1984). A massa específica da areia natural foi de $2,623 \mathrm{Kg} / \mathrm{dm}^{3}$ e a da cinza pesada foi de $1,779 \mathrm{Kg} / \mathrm{dm}^{3}$. A granulometria da areia utilizada está ilustrada na Figura 1 .

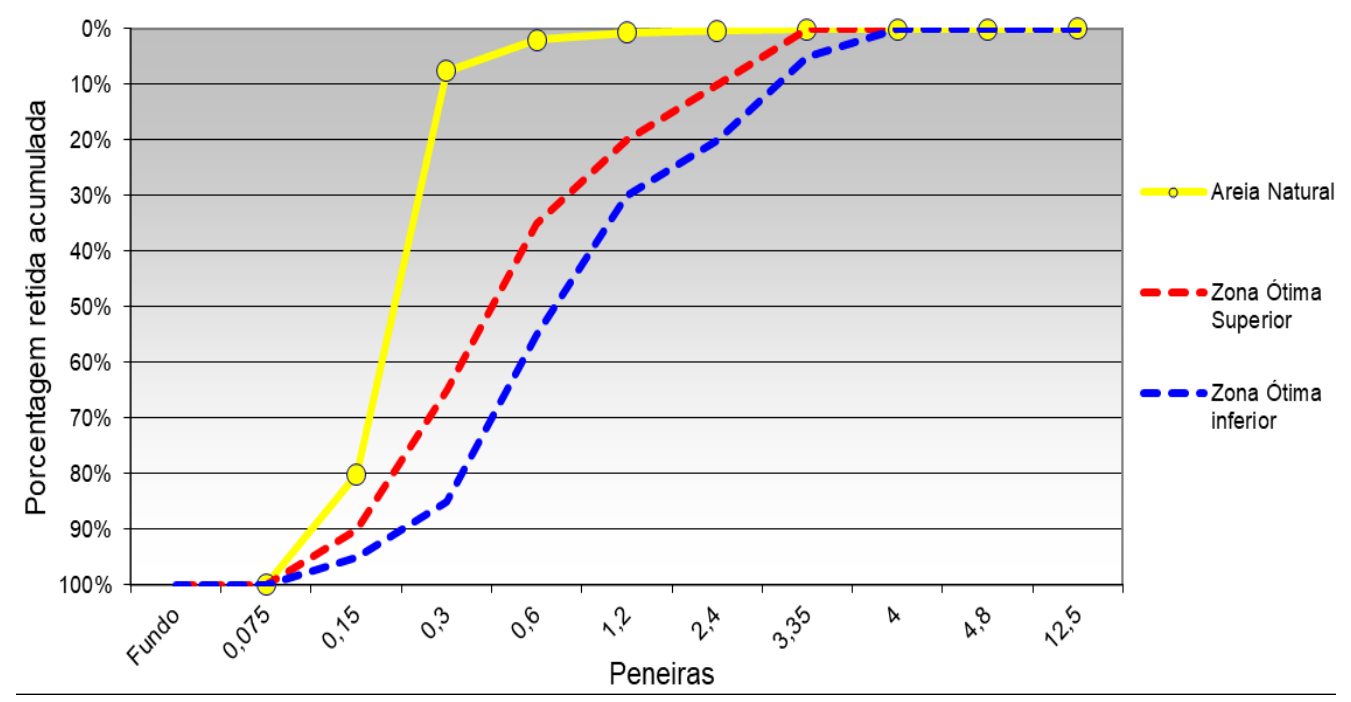

Figura 1 - Granulometria da areia natural

O agregado miúdo utilizado no presente estudo é um agregado comumente utilizado pelas empresas da região da Grande Florianópolis - Santa Catarina. Geralmente ela é utilizada combinada com uma areia de britagem (areia artificial), entretanto decidiu-se utilizar somente a areia natural pois seu percentual de utilização é maior do que a de britagem. Assim, para melhor verificar a influência da substituição da cinza pesada em relação a areia natural utilizou-se somente a areia natural como agregado miúdo.

$O$ aditivo utilizado no estudo foi o dispersante de terceira geração MC Powerflow 4000 obtido por meio de uma empresa que fabrica aditivos para misturas cimentícias.

O programa experimental foi planejado com o intuito de estudar as propriedades de argamassas cimentícias produzidas com cinza pesada não beneficiada em substituição a areia natural, tanto no estado fresco quanto endurecido. Para tal, foram produzidas argamassas com relação ligante/agregado miúdo 1:2 e 1:3, com substituições de cinza pesada (em massa) ao agregado miúdo nos teores de $20 \%, 40 \%$ e $60 \%$. A figura 2 , apresenta o resumo dos ensaios realizados nas argamassas produzidas com cinza pesada não beneficiada. Os procedimentos e detalhes de cada ensaio serão discutidos posteriormente.

As misturas foram realizadas em uma argamassadeira planetária de eixo vertical com o volume de mistura variando entre 1 e 1,5 litros. Após o procedimento de mistura, foram realizados os ensaios no estado fresco e, posteriormente, moldados corpos de prova $(50 \times 100 \mathrm{~mm})$ para os ensaios no estado endurecido na idade de 28 dias.

Em seguida, os CPs foram acondicionados em tanques contendo água e cal até a idade de execução dos ensaios no estado endurecido. Ainda, os exemplares foram capeados a fim de promover uma superfície de contato plana entre os corpos de prova e os pratos da prensa. 


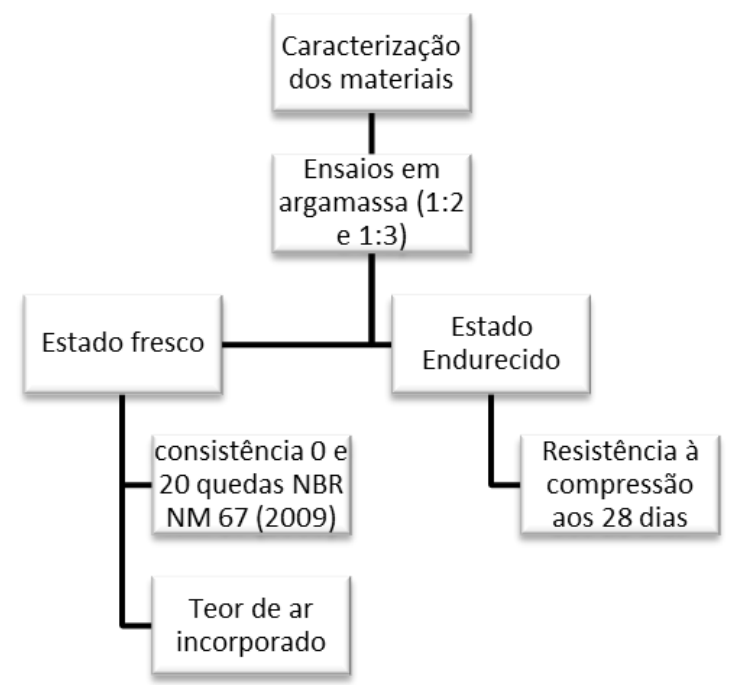

Figura 2 - Ensaios adotados para a determinação das propriedades no estado fresco e endurecido das argamassas

No que tange a avaliação das propriedades no estado fresco das argamassas foi realizado o ensaio do índice de consistência conforme ABNT NBR 13276 (2016). O objetivo foi verificar a influência da substituição na consistência e trabalhabilidade da argamassa. Em relação aos ensaios no estado endurecido, foram realizados ensaios de resistência à compressão seguindo as diretrizes da ABNT NBR 13279 (2005).

\section{Resultados e discussões}

\section{$1 . \quad 3.1 \quad$ Estado fresco}

Como a substituição de cinza pesada em relação ao agregado natural foi realizada em massa, e a massa específica da cinza pesada é menor do que a da areia natural, foi necessário realizar a correção dos traços para produção de 1 metro cúbico de argamassa. Os novos traços das argamassas estão apresentados na tabela 3.

Conforme pode ser verificado na tabela 2 , as argamassas que tiveram substituição do agregado miúdo natural por cinza pesada, tiveram uma redução de consumo de cimento Portland em relação à argamassa de referência. Nota-se também que, o volume adicionado de cinza pesada é maior do que o volume retirado de areia natural, portanto o volume de mistura é modificado e consequentemente, a quantidade dos insumos para a sua produção. Os resultados para o ensaio de consistência das argamassas estão ilustrados nas Figuras 3 e 4 .

Tabela 2 - Traço das argamassas estudadas

\begin{tabular}{|c|c|c|c|c|c|c|c|}
\hline \multicolumn{4}{|c|}{ Volume produzido real para 1000 litros } & \multicolumn{4}{|c|}{ Volume produzido real para 1000 litros } \\
\hline \multirow{2}{*}{$1 ; 2$} & \multicolumn{3}{|c|}{ Composição em massa } & \multirow{2}{*}{$1 ; 3$} & \multicolumn{3}{|c|}{ Composição em massa } \\
\hline & Referência & $20 \%$ & $40 \%$ & & Referência & $20 \%$ & $40 \%$ \\
\hline cimento $(\mathrm{kg})$ & 638,4 & 614,4 & 592,1 & cimento $(\mathrm{kg})$ & 529,1 & 504,5 & 482,2 \\
\hline areia natural $(\mathrm{kg})$ & 1083,5 & 834,1 & 602,9 & areia natural (kg) & 1346,9 & 1027,5 & 736,4 \\
\hline cinza pesada $(\mathrm{kg})$ & 0 & 208,5 & 401,9 & cinza pesada (kg) & 0 & 256,9 & 491 \\
\hline água (kg) & 380,2 & 365,8 & 352,6 & água (kg) & 315,1 & 300,4 & 287,1 \\
\hline Massa total $(\mathrm{kg})$ & 2102,1 & 2022,8 & 1949,4 & Massa total (kg) & 2191,1 & 2089,4 & 1996,7 \\
\hline $\begin{array}{l}\text { volune produzido } \\
\text { (I) }\end{array}$ & 1000 & 1000 & 1000 & $\begin{array}{l}\text { volune produzido } \\
\text { (I) }\end{array}$ & 1000 & 1000 & 1000 \\
\hline
\end{tabular}




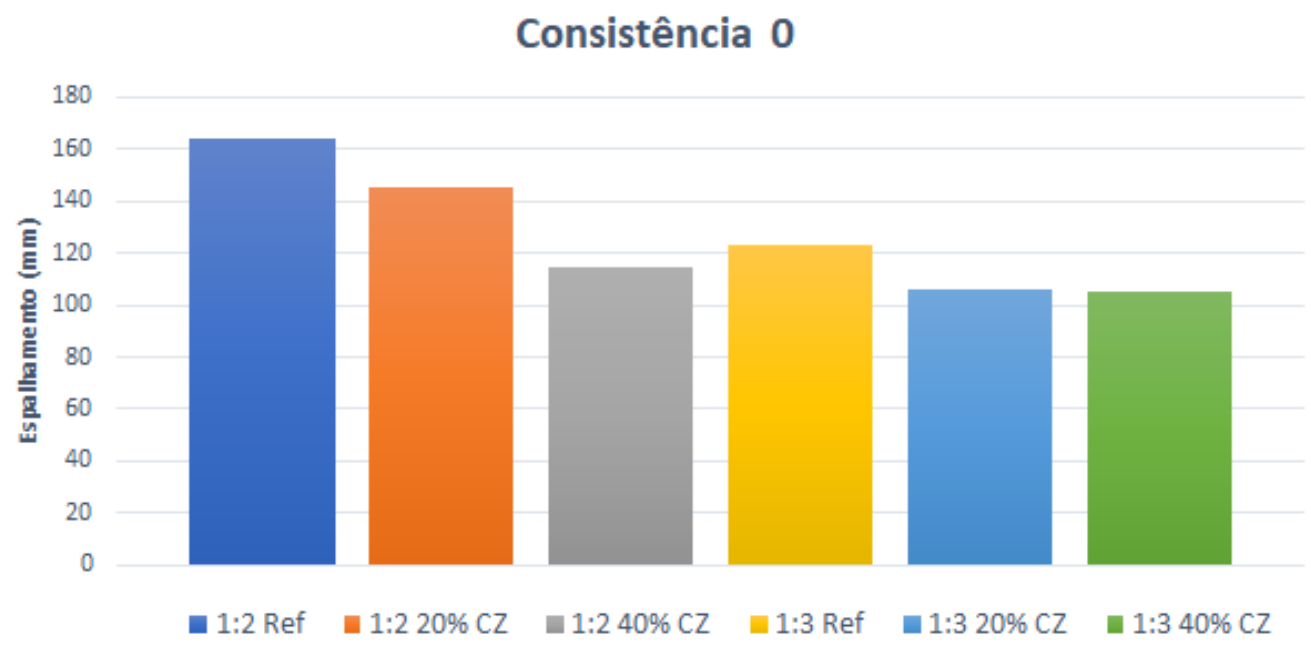

Figura 3 - Ensaio de consistência das argamassas com 0 quedas

\section{Consistência 20}

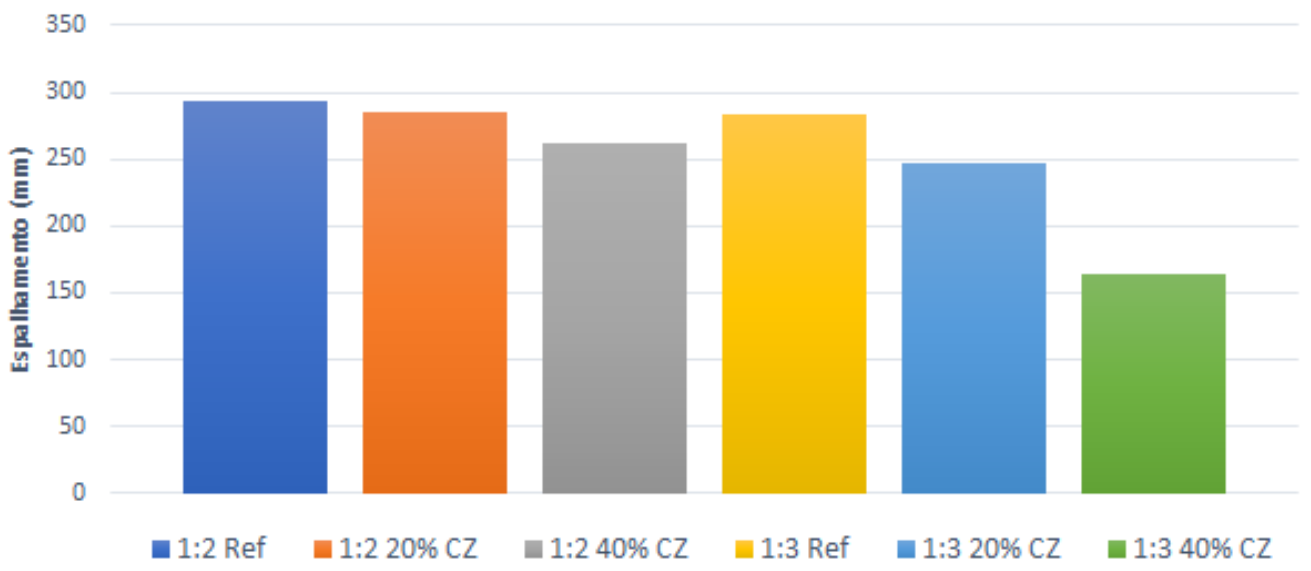

Figura 4 - Ensaio de consistência das argamassas com 20 quedas

O índice de consistência da argamassa foi medido no sem queda (consistência 0) e após 20 quedas (consistência 20). Pode ser verificado que há um padrão no comportamento das argamassas, esse padrão indica que quanto maior a substituição em massa de areia natural por cinza pesada (CZ) menor será o espalhamento da argamassa. Esse comportamento pode ser explicado devido a massa específica da cinza pesada ser menor do que a massa específica da areia natural. Assim, quando se faz a substituição em massa de areia natural por cinza pesada coloca-se maior volume de sólidos para uma mesma mistura e assim diminui a fluidez do sistema, acarretando menores índices de consistências.

Ainda, ressalta-se que uma diminuição no espalhamento das argamassas com relação ligante:agregado miúdo 1:3 comparadas com as argamassas com relação 1:2, com mesmas relações água/cimento. Isso é esperado já que com a relação 1:3 se tem menor quantidade de água disponível no sistema em relação às argamassas com relação 1:2. Com menor quantidade de água disponível para lubrificar as partículas no sistema, deve haver uma diminuição no índice de consistência das argamassas.

Além disso, com os resultados do estado fresco pode-se traçar um gráfico relacionando a quantidade de ar incorporado pelas misturas com o teor de aditivo utilizado. Esse gráfico é ilustrado na Figura 5.

A figura 5 apresenta que a maior substituição de areia natural por cinza pesada exigiu maior quantidade de aditivo para atingir o espalhamento desejado. Isso pode ser explicado devido ao aumento do volume de sólidos da mistura gerado pela substituição. Além de que, sabe-se que a cinza pesada é um material poroso, portanto absorve maior quantidade de água do sistema e demanda maior quantidade de aditivo para atingir 
a mesma consistência. Mangi et al. (2019) indica que a superfície irregular e porosa do material contribui para o maior consumo de água para que a mistura atinja a mesma consistência.

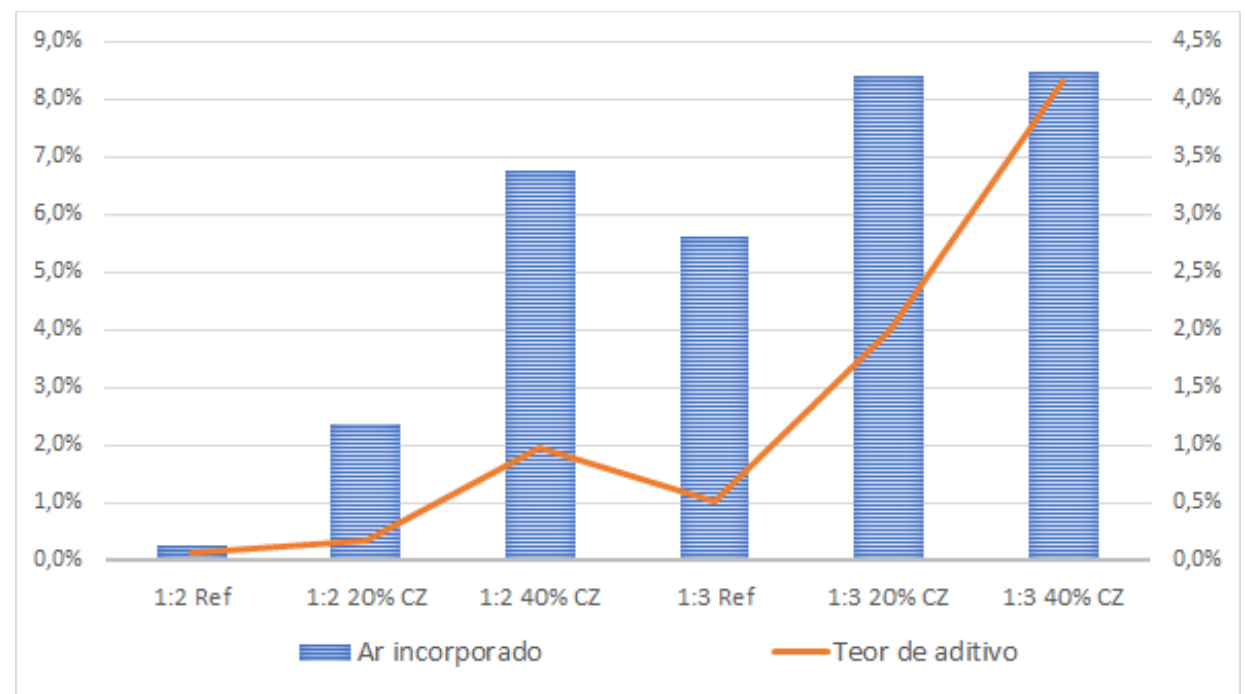

Figura 5 - Correlação entre teor de ar incorporado e quantidade de aditivo utilizado em cada argamassa

Observa-se que o aumento da relação ligante:agregado miúdo acarretou em um aumento no consumo de aditivo. Isso se explica pela diminuição da água livre para lubrificar a mistura, já que para maiores relações ligante:agregado, com mesma relação água/cimento, ocorre a diminuição do ligante e água para um mesmo volume de mistura.

Verifica-se também que, o aumento do consumo de aditivo nas misturas causou uma tendência de aumento da incorporação de ar. Verifica-se que devido à demanda de grandes teores de aditivo superplastificantes as argamassas incorporaram grandes quantidades de ar. Collepardi (1976), Ramachandram e Malhotra (1998), afirmam que superdosagens de aditivos superplastificantes em matrizes cimentícias podem resultar em altos valores de ar incorporado. Segundo Raabe (1991) e Gjorv (1992), aditivos redutores de água de alta eficiência, como os superplastificantes, tendem a gerar maior incorporação de ar em concretos de alto desempenho. Sabe-se que uma maior incorporação de ar em uma matriz cimentícia pode resultar em redução nas suas propriedades mecânicas.

2.

3.2 Estado endurecido

A seguir serão discutidos os ensaios de resistência à compressão das argamassas produzidas com e sem a substituição de cinza pesada. Os resultados do ensaio aos 28 dias são ilustrados na Figura 6.

Conforme pode ser verificado pelos resultados de resistência à compressão aos 28 dias na figura 6, houve uma tendência da argamassa produzida com a substituição de areia natural por cinza pesada no teor de $20 \%$ resultando em menor resistência à compressão do que as demais argamassas estudadas. Isso pode ser explicado pela diferença de massa específica entre os agregados, que suscita em um traço mais pobre quando há a substituição de areia natural por cinza pesada. Sendo a substituição da areia por cinza pesada realizada em massa, e sendo a massa específica da cinza pesada menor em comparação à da areia, o volume de sólidos é maior na argamassa com cinza pesada em sua composição. Além disso, ensaios à compressão para idades mais avançadas podem resultar na diminuição da diferença da resistência à compressão das argamassas de referência e as com cinza pesada, isso porque, pode ocorrer atividade pozolânica com o passar do tempo para as argamassas com cinza pesada (CHERIAF, et al. 1999).

Assim, fez-se o desempenho de quilograma utilizado para produção de cada argamassa para atingir $1 \mathrm{Mpa}$ de resistência à compressão. Esse índice de desempenho ajuda a identificar a mistura que apresenta os melhores resultados no quesito de resistência à compressão. Esses resultados são ilustrados na Figura 7. 


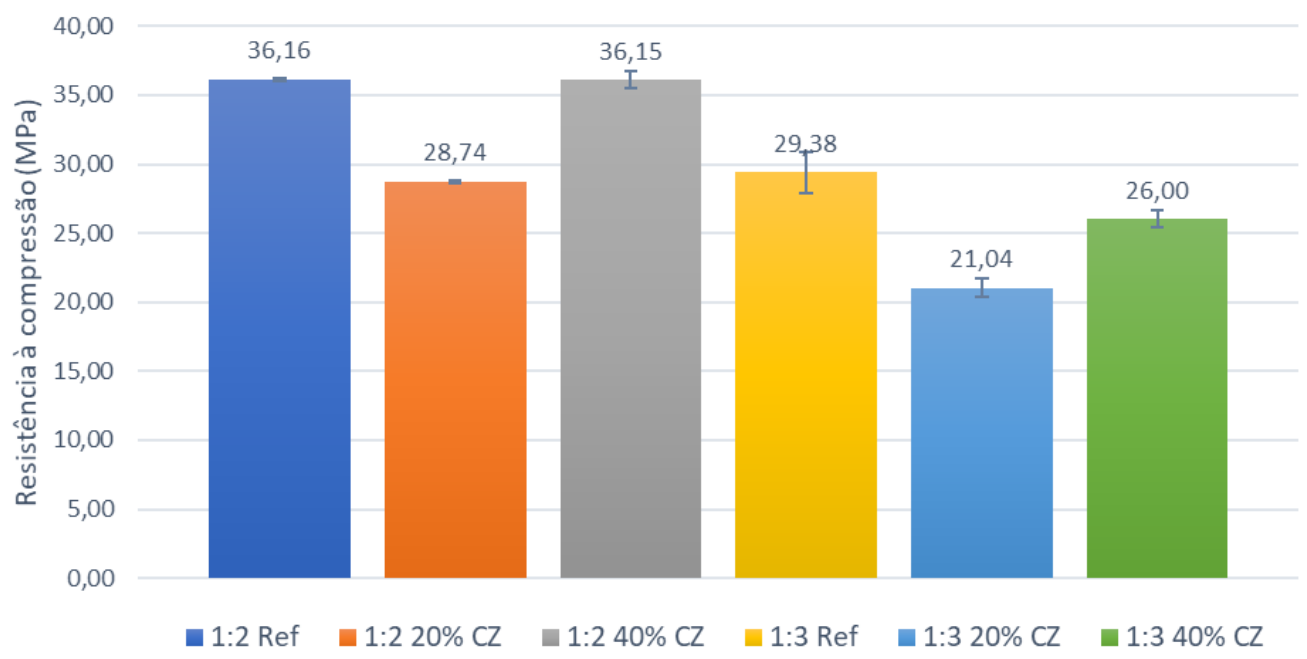

Figura 6 - Resultados de resistência à compressão das argamassas aos 28 dias

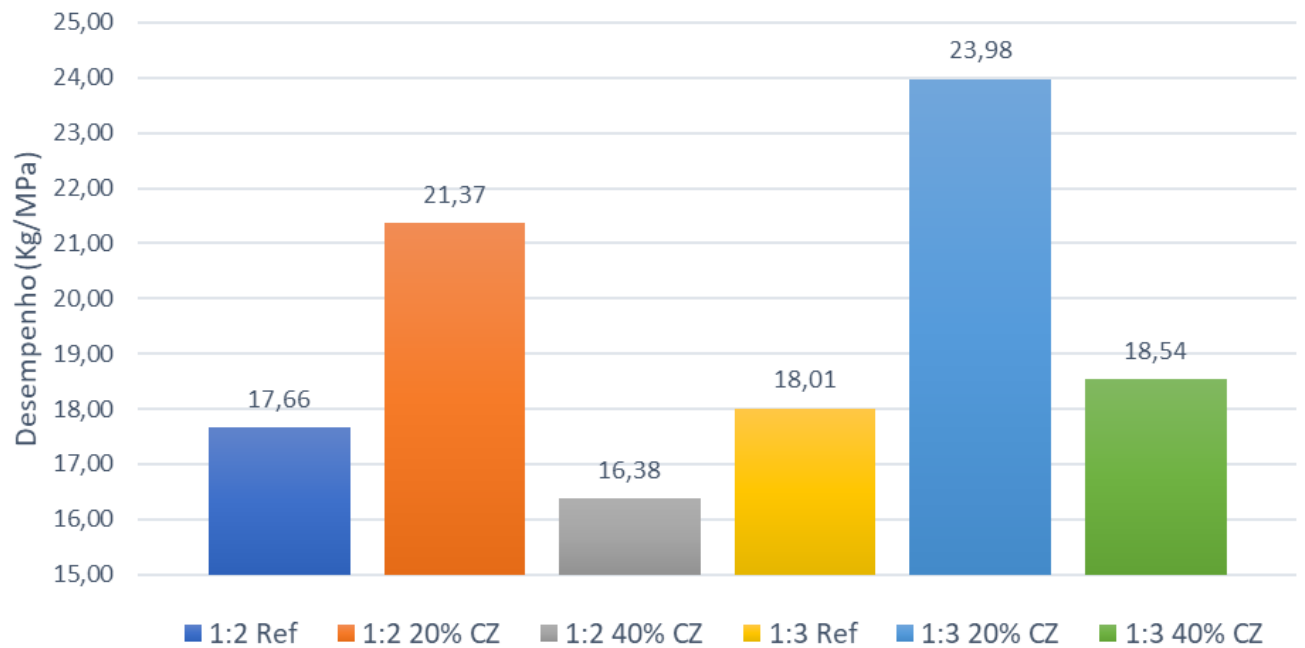

Figura 7 - Índice de desempenho da quantidade de cimento Portland utilizado para o ganho de 1 Mpa na resistência à compressão das argamassas aos 28 dias.

Como apresentado no gráfico da figura 7, após comparação entre a argamassa de referência e as argamassas com substituição do agregado miúdo natural por cinza pesada, nota-se que os maiores índices de desempenho entre as misturas foram resultado da substituição de $20 \%$ de areia natural por cinza pesada. Percebe-se também que o traço de 1:3 (ligante:agregado miúdo) apresentou maiores índices de desempenho se comparados individualmente com o traço 1:2 (ligante:agregado miúdo).

Quanto maior o valor do índice de desempenho da matriz cimentícia indica que a mistura necessita de maior quantidade de ligante hidráulico para atingir a mesma resistência à compressão aos 28 dias. Assim, verificase que, independente da relação ligante:agregado miúdo, a utilização de cinza pesada em argamassa em substituição em relação a massa de agregado miúdo resultou em aumento na demanda de cimento Portland para a substituição de $20 \%$ para atingir mesma resistência à compressão em relação à argamassa de referência. Ainda, pode-se verificar que para a substituição de $40 \%$ o desempenho da mistura foi o mesmo que a mistura de referência, independente da relação água/ligante utilizada. Segundo Abdulmatin et al. (2018) os finos da cinza pesada podem preencher poros menores que não eram preenchidos anteriormente e assim promovendo uma ação de refinamento de poros na matriz, o que pode acarretar em melhorias nas propriedades mecânicas e na durabilidade da mistura. 
Com os materiais e os métodos utilizados no presente estudo, os resultados da pesquisa em questão inferiram que:

- A utilização cinza pesada em susbstituição parcial em massa ao agregado miúdo natural demandou maior quantidade de aditivo dispesante para obter mesma consistência do que a argamassa de referência;

- A argamassa produzida com $60 \%$ de susbstituição de agregado miúdo natural por cinza pesada não obteve mesma consistência das demais argamassas independentemente da quantidade de aditivo dispersante utilizado;

- O maior consumo de aditivo resultou em maior teor de ar incorporado pelas misturas;

- A substituição com $40 \%$ de susbstituição de agregado miúdo natural por cinza pesada obteve mesmo desempenho de resistência à compressão aos 28 dias para o mesmo consumo de cimento Portland.

\section{Referências}

ABDULMATIN, A.; TANGCHIRAPAT, W.; JATURAPITAKKUL, C. An investigation of bottom ash as a pozzolanic material. Construction and Building Materials. Vol, 186. Pages,155-162. 2018. https://doi.org/10.1016/i.conbuildmat.2018.07.101.

ASSOCIAÇÃO BRASILEIRA DE NORMAS TÉCNICAS NBR 6508: Determinação da massa especifica. Rio de Janeiro, 1984.

. NBR NM 67: Concreto - Determinação da consistência pelo abatimento do tronco de cone Rio de Janeiro, 1998.

NBR NM 248: Agregados - Determinação da composição granulométrica. Rio de Janeiro, 2003.

CHERIAF, M.; ROCHA, J. C.; PÉRA, J. Pozzolanic properties of pulverized coal combustion bottom ash. Cement Concrete Research. Vol, 29. Pages, 1387-1391. 1999. https://doi.org/10.1016/S0008-8846(99)00098-8.

COLLEPARDI, M. Assessment of the "rheoplasticity" of concretes. Cement and Concrete Research. v. 6, n.3, p. 401-408. 1976.

FEDERAL HIGHWAY ADMINISTRATION: TURNER FAIRBANK HIGHWAY RESEARCH CENTER. User guidelines for waste and by-product material in pavament construction. United States Departament of transport. 1998.
Acesso
em
02/12/2020.
Disponível
em

https://www.fhwa.dot.gov/publications/research/infrastructure/pavements/97148/008.cfm.

GJORV, O. E. MALHOTRA, V. M. High strength concrete. Advances in Concrete Technology. In: (ed) . Otawa: Energy Mines Resources. p.21-78, 1992

JATURAPITAKKUL, C. CHEERAROT, R. Development of bottom ash as pozzolanic material. Journal Materials Civil Engineering. vol 15. p.48-53. 2003.https://doi.org/10.1061/(asce)0899-1561(2003)15:1(48).

KLEE, $\mathrm{H}$. The cement sustainability initiative. Proceeding of Institution of Civil Engineers Engineering Sustainability. Institute of Civil Engineers: London, UK, 2004.

MANGI, S. A.; WAN IBRAHIM, M. H.; JAMALUDDIN, N.; ARSHAD, M. F.; PUTRA JAYA, R. Shortterm effects of sulphate and chloride on the concrete containing coal bottom ash as supplementary cementitious material. Engineering Science and Technology, an International Journal. Vol, 22. Pages, 515-522. 2019. https://doi.org/10.1016/i.jestch.2018.09.001.

MEHTA, P. K.; MONTEIRO, P. J. M. Concreto: microestrutura, propriedades e materiais. 2. ed. São Paulo: Ibracon, 2014.

MEYER, C. The greening of the concrete industry. Cement Concrete Composites. Volume 31, páginas 601605, 2009.

RAABE, A. L. Aditivos Superplastificantes em Concretos de Cimento Portland. Dissertação de Mestrado. Escola de Engenharia, Curso de Pós-Gradução em Engenharia Civil da Universidade Federal do Rio Grande do Sul. Porto Alegre, Brasil, 144pg, 1991. 
RAMACHANDRAN, V. S. MALHOTRA, V. M. Superplasticizers: Properties and Applications in Concrete. Capítulo 7. Pg 410 - 518. 1998. ISBN: 978-0660173931.

SINGH, M. Coal bottom ash, Waste Supplementary Cementitious Materials in Concrete: Characterisation, Properties and Applications. Woodhead Publishing Series in Civil and Structural Engineering. p. 3-50. 2018.https://doi.org/10.1016/b978-0-08-102156-9.00001-8.

SINGH, M. SIDDIQUE, R. Strength properties and micro-structural properties of concrete containing coal bottom ash as partial replacement of fine aggregate. Construction and Building Materials. vol 50. p.246256. 2014.https://doi.org/10.1016/i.conbuildmat.2013.09.026. 